\title{
Correction to: High School Students' Use of Technology to Make Sense of Functions Within the Context of Geometric Transformations
}

\section{Karen Hollebrands ${ }^{1}\left[\right.$ - Allison W. McCulloch ${ }^{2} \cdot$ Samet Okumus $^{3}[$}

Published online: 2 April 2021

(C) Springer Nature Switzerland AG 2021

\section{Correction to: Digit Exp Math Educ https://doi.org/10.1007/s40751-021-00085-9}

In the original version of the article there was an error in the author affiliation.

Allison McCulloch's affiliation should be the University of North Carolina at Charlotte.

The original article has been corrected.

Publisher's Note Springer Nature remains neutral with regard to jurisdictional claims in published maps and institutional affiliations.

The online version of the original article can be found at https://doi.org/10.1007/s40751-021-00085-9

Karen Hollebrands

kfholleb@ncsu.edu

1 North Carolina State University, Raleigh, NC, USA

2 University of North Carolina at Charlotte, Charlotte, NC, USA

3 Recep Tayyip Erdoğan University, Rize, Turkey 